\title{
Green Synthesis of Silver Nanoparticle from Photograph Wastewater Using Hylocereus Undatus Skin Extract
}

\author{
IS FATIMAH, ${ }^{*}$ and ARSY FARIDHATUNNISA \\ Chemistry Department, Universitas Islam Indonesia, KampusTerpadu UII, JI. Kaliurang Km 14, \\ Sleman, Yogyakarta, 55581, Indonesia. \\ ${ }^{\star}$ Corresponding author E-mail: isfatimah@uii.ac.id \\ http://dx.doi.org/10.13005/ojc/330322 \\ (Received: May 07, 2017; Accepted: May 31, 2017)

\begin{abstract}
Green synthesis of nanoparticle utilizing plant extract is developing technique recently. A relative cheap and non-hazardous substance is an advantageous for this. Regarding to the potency of dragon fruit (Hylocereus undatus), this research employed the extract of dragon fruit waste (skin) and also photography waste as sources for synthesis. Effect of preparation method was studied by varying reflux and microwave irradiation method. Bioreductor of Hylocereus undatus was prepared by maceration of dried Hylocereus undatus skin. The extract was mixed with photograph wastewater followed by reflux and aging method separately. The nanoparticle formation was measured by using UV-Vis spectrophotometry and particle size analyzer. The nanoparticle solution was tested for antibacterial activity antioxidant activity by DPPH method. The result indicates that the extract of Hylocereus undatus is potential to be used as bioreductor in silver nanoparticle synthesis. The nanoparticles are found to have particle size in between 20-100nm. Nanoparticles are active antioxidant. The antioxidant activity of derived nanoparticles is influenced by method in that by reflux method the antioxidant activity is at around $88 \%$ while by $00 \%$ while by aging method the activity is $81.78 \%$. Both values are higher compared to synthesis by using silver standard solution with the same methods.
\end{abstract}

Keywords: Hylocereus undatus, nanoparticle synthesis, bioreductor

\section{INTRODUCTION}

Nanotechnology is one of recent technology that has many advantages. The application of Nanotechnololgy is not only for delivering some drugs in pharmacy's field, but also can be used for industry and daily life. By the size $<100 \mathrm{~nm}$, the possibility of interacting particles to form a conjugate in molecular and cellular level will increase ${ }^{1}$.
Within the nanotechnology scheme, synthesis of metal nanoparticles is usually obtained by chemical and physical approaches, one of these is by using plant extract as green reductor. Besides inexpensive, it is also considered friendly-environment and the use of plant extract has economically advantageous due to its availability ${ }^{2}$. Many reports present the potency of some plants extract containing flavonoid, 
flavon, polyphenol, natural dyes and some organic functional group for silver nanoparticle (Ag NPs) production $^{1,3}$.

Red dragon fruit (DF)has known as fruit with antitumor, antioxidant, and anti-inflammatory activity. Red dragon fruit contains $\beta$-amyrin $23.39 \%$; $\gamma$-sitosterol $19.32 \%$; octadecane $9.25 \%$; heptacosane $5.25 \%$; campesterol $5.27 \%$; nonacosane $5.02 \%$; trichloroacetic acid, hexadexyl ester $5.21 \%$ and dominated extract was determined as triterpenoids $23,39 \%$ and steroids $19.32 \%^{4-6}$. Red dragon is easily to grow but there is no information for skin utilization. From the characteristic and contents of red dragon fruit consist of polyphenol and reduction potential, it can be predicted that the content of its skin is also potential for reduction in the metal nanoparticles synthesis.

In other side, photography wastewater is one of potential chemical waste from industrial activities containing silver metal waste. In fact that the content of photography waste is silver in major, the trial on utilization of photography waste as source for synthesis of Ag NPs is interesting topic. By combining the potency of red dragon fruit skin extract and photography waste, purpose of this research is to study is the potency of Ag metal content in photography waste water and extract of red dragon fruit extract in synthesis of Ag NPs. Evaluation of NPs formation was performed by UV-Visible spectrophotometric analysis, particle size analysis and antioxidant activity test by using 2,2-diphenyl1-picrylhydrazyl (DPPH) method.

\section{MATERIALS AND METHOD}

\section{Materials}

Silver nitrat, DPPH, methanol, and ethanol were purchased from Merck-Millipore (Germany). Red dragon fruit was obtained from Sleman District, Yogyakarta, Indonesia. Photography wastewater was obtained from Clinical laboratory in Sleman District, Yogyakarta, Indonesia. From analysis by using atomic absorption spectroscopy (AAS) Perkin Elmer, it is found that the concentration of Ag in water is $2 \times 10^{-4} \mathrm{M}$.

\section{Preparation of plant extract}

Deagon fruit (DF) skin was washed by water before drying at $60{ }^{\circ} \mathrm{C}$ for 24 hours. $3.5 \mathrm{~g}$ skin of dried DF skin was macerated in ethanol: water (1:1) solvent over shaking for 15 minutes. The red solution was then filtered off from the mixture and furthermore called as dragon fruit extract (DFE).

\section{Biosynthesis of Ag NPs}

Biosynthesis of Ag NPs was conducted by mixing $5 \mathrm{~mL}$ of DFE with $95 \mathrm{~mL}$ of standard silver solution $\left(10^{-3} \mathrm{M}\right)$. Two varied method: aging and reflux for $2 \mathrm{~h}$ were applied. In order to evaluate the potency of PW as Ag source, similar procedures were applied for PW. The samples are designated as Ag NPs and Ag NPs (PW) for the nanoparticles obtained by using standard solution of $\mathrm{Ag} \mathrm{NO}^{3}$ and $\mathrm{PW}$ respectively.

\section{Characterization of silver nanoparticles}

Characterization of Ag NPs was conducted by using UV-Vis Spectrophotometer (HITACHI U-2010) and particle size analyzer HORIBA-X, HORIBA Scientific (Kyoto, Japan).

\section{Antioxidant activity}

The antioxidant activity of Ag NPs was determined by DPPH method. DPPH solution was prepared in $95 \%$ methanol. $0,2 \mathrm{~mL}$ extract of skin Red Dragon Fruit was dillluted by $2 \mathrm{~mL}$ methanol and the mixtured mixed with $2 \mathrm{~mL}$ freshly prepared $\mathrm{DPPH}$ and wait for 30 minutes. The solution was analyzed for absorbance at $517 \mathrm{~nm}$ usingUV-Spectrophotometer. Control sample was prepared without the addition of any extract and nanoparticles. The mixture of ethanol : water, $12.5: 12.5 \mathrm{~mL}$ was used as blank.

\section{RESULT AND DISCUSSION}

\section{Synthesis of Ag NPs}

The formation of Ag NPs during synthesis can be monitored by using UV-Visible spectrophotometry analysis. Ag NPs express the plasmon resonance formation at the range of $300-400 \mathrm{~nm}$. Some factors affecting the formation of plasmon resonance are the method of reaction, $\mathrm{pH}$, mixture composition, etc. In this research, effect of method was varied. Based on many papers reported the synthesis over reflux method, in this investigation the comparison on reflux method and aging method as well as the comparison with the use of silver solution were conducted. The spectra are presented in Figure 1.

UV-Vis Analysis results indicated that there is a specific specta at around 550nm correspond 
to the content of active compounds in DFE which is also appeared by red color of the extract. As the extract was mixed with $\mathrm{AgNO} 3$ solution, there is an intense peak at $390 \mathrm{~nm}$ as indication of nanoparticles formation along the disappearance of $550 \mathrm{~nm}$ peak. Those specific peaks at around $380 \mathrm{~nm}-410 \mathrm{~nm}$ are theindication of plasmon resonance formation ${ }^{2,7}$. The corresponding peak was shifted to 400nm after aging and into $409 \mathrm{~nm}$ after refluxing process. The shifts are related to reduction reaction of $\mathrm{Ag}^{+}$solution by the extract and express the change of nanoparticles size. Similar trend is also found in the PW utilization as silver ion source. From the comparison, the use of PW gives slightly lower wavelength compared to that is presented by $\mathrm{Ag}$ NPs by using Ag standard solution. The formation of Ag NPs can be interpreted from visual change of the color during the synthesis (Figure 2).

Furthermore, the formation of Ag NPs was studied by particle size analysis with dynamic scaterring method and the results are depicted in Figure 3.

From the particle size distribution it is confirmed that DFE produced nanoparticle formation as indicated by the mean size of Ag NPs obtained by silver solution at around 103-112 nm. By comparison on the effect of reflux method it is found that refluxing gives smaller nanoparticle size. Similar pattern is also depicted by the utilization of PW as Ag source. However, a specific finding was appeared by $\mathrm{Ag}$ NPs from PW in that the aging method did not give nanoparticle since the particle distribution lays on more than $5000 \mathrm{~nm}$. Refluxing gives smaller size in the heterogeneous distribution with the modal pores at $100 \mathrm{~nm}$ and $3000 \mathrm{~nm}$. The patterns suggest the temperature effect during silver reduction. Fast reduction obtained during reflux method accelerate the formation of nanoparticle and minimize the aggregation of particles as shown by the aging method. The phenomenon is related to that was
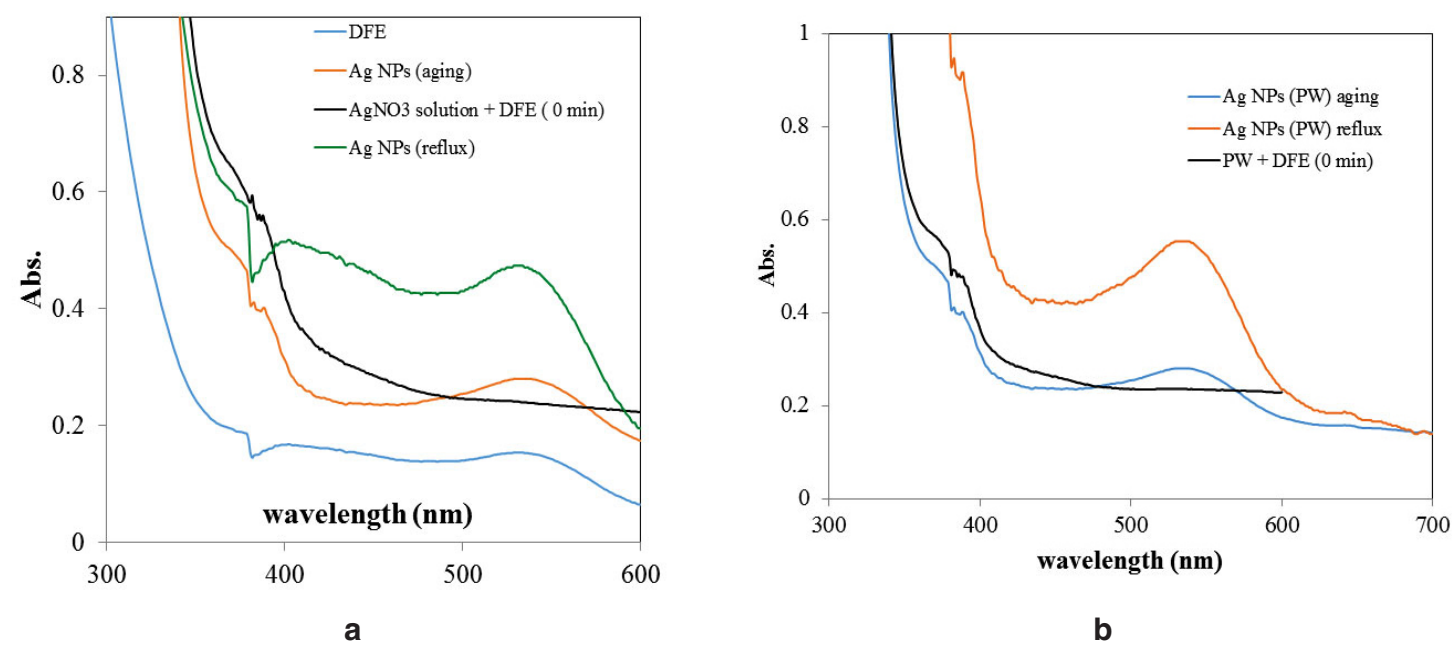

Fig. 1.:The change of UV-Vis spectra during Ag NPs synthesized by using (a) $\mathrm{AgNO}_{3}$ solution (b) PW

Table 1: Data of antioxidant activity of Ag NPs

\begin{tabular}{ccccc}
\hline No & $\begin{array}{c}\text { Ag precursor } \\
\text { source-method }\end{array}$ & $\begin{array}{c}\text { Initial Absorbance } \\
\mathbf{( 5 1 7 n m )}\end{array}$ & $\begin{array}{c}\text { Final Aborbance } \\
\mathbf{( 5 1 7 n m )}\end{array}$ & $\begin{array}{c}\text { Antioxidant Activity } \\
\mathbf{( \% )}\end{array}$ \\
\hline 1 & Ag NPs (reflux) & 0.931 & 0.126 & 86.47 \\
2 & Ag NPs (aging) & 0.834 & 0.262 & 68.59 \\
3 & Ag NPs PW (reflux) & 0.656 & 0.073 & 88.87 \\
4 & Ag NPs PW (aging) & 0.697 & 0.127 & 81.78 \\
\hline
\end{tabular}


reported by previous investigation on the thermal effect in silver reduction toward size and shape of nanoparticles ${ }^{8}$.

\section{Antioxidant activity}

Antioxidant activity of Ag NPs was evaluated by DPPH assay. The test has been the most accepted model for evaluating the free radical scavenging activity of any new drug and potential agent. When a solution of DPPH is mixed with that of a substance that can donate a hydrogen atom, then this gives rise to the reduced form (Diphenylpicrylhydrazine; non radical) with the loss of this violet colour 9 . The color was measured at $517 \mathrm{~nm}$ and antioxidant activity was measured by following equation:

$$
\text { Antioxidant Activity }=\frac{\left(A b s_{i}-A b s_{f}\right)}{A b s_{i}} .100 \%
$$

With $\mathrm{Abs}_{\mathrm{i}}$ and $\mathrm{Abs}_{\mathrm{f}}$ are initial and final absorbance respectively.

The result of tests are listed in Table 1.

Data in Table 1 confirmed that Ag NPs obtained from PW solution exhibit antioxidative activity with the activity at around $81-88 \%$ while $\mathrm{Ag}$

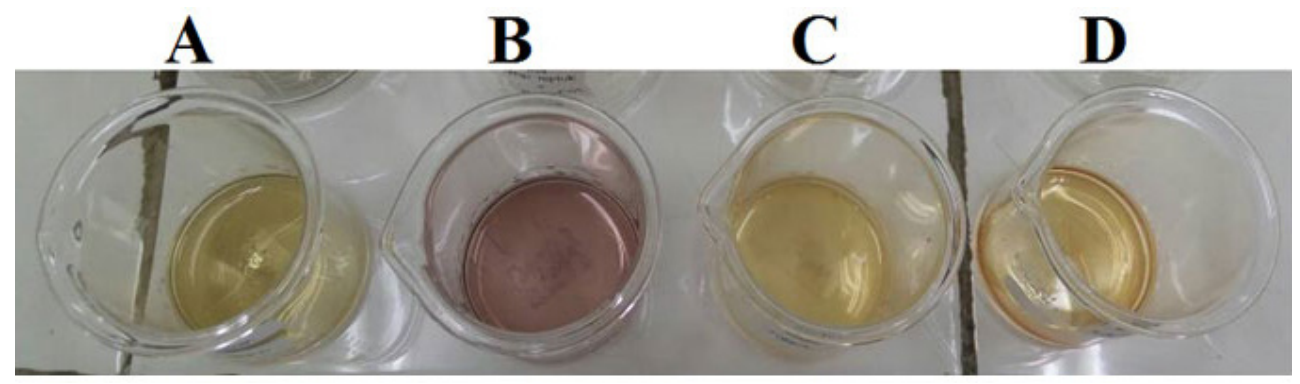

Fig. 2: AgNPs synthesized from (a) Ag standard solution using reflux method (b) Ag standard solution using aging method (c) PW using reflux method (d) PW using aging method

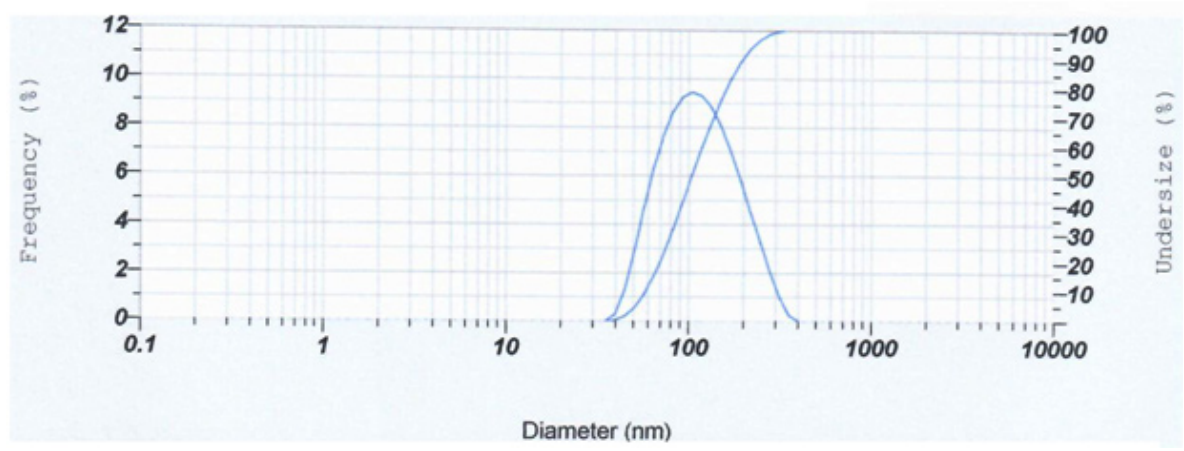

(a)

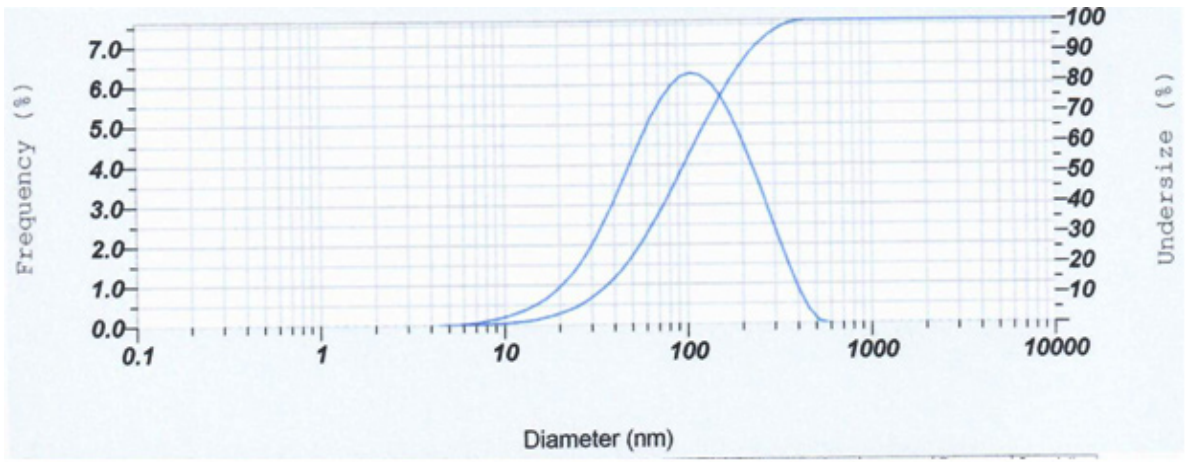

(b) 




(c)

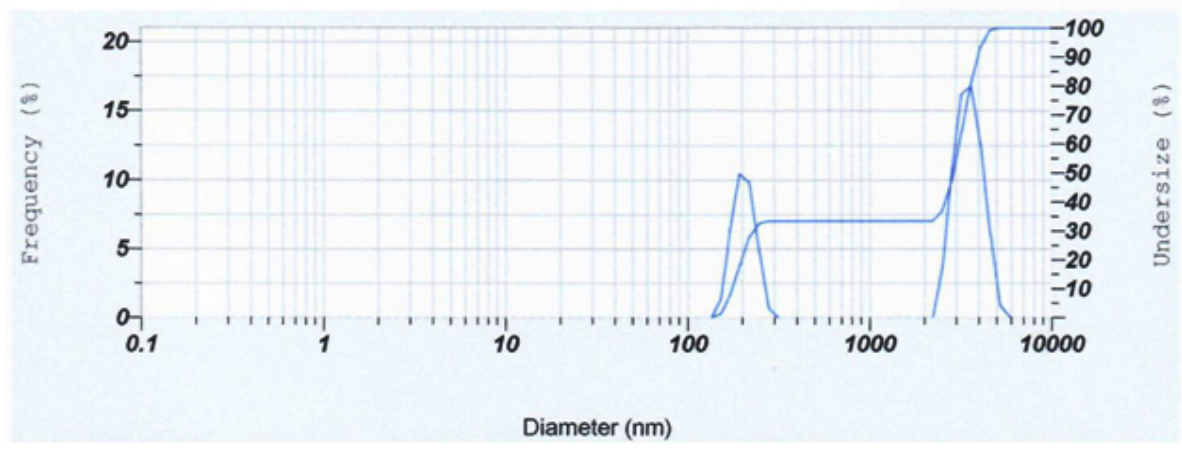

(d)

Fig. 3: Particle size distribution of Ag NPs obtained by (a) Ag standard solution using reflux method (b) Ag standard solution using aging method (c) PW using reflux method (d) PW using aging method

NPs obtained from Ag standard solution have lower activity. Ag NPs obtained from PW over reflux method gives higher antioxidant activity $(88.87 \%)$ compared to Ag NPs over aging method ( $81.78 \%)$. From the pattern, the data suggest the effect of refluxing method to give higher activity.

\section{CONCLUSION}

From the data it is concluded that dragon fruit extract has potential to be reductor in Ag NPs biosynthesis. The extract show the capability to form nanoparticles and affected by the source of $\mathrm{Ag}$ solution as well as biosynthesis mechanism. From compared experiments, photograph wastewater expressed the potency in Ag NPs formation over reflux method. The Ag NPs demonstrated the antioxidant activity.

\section{ACKNOWLEDGEMENT}

Authors thank to Chemistry Department, Universitas Islam Indonesia for Research Grant No: 001/KIM/III/2017

\section{REFERENCES}

1. Fatimah I.;Eksakta. 2017;17(1):66-85.

2. Firdhouse MJ; LalithaP.;2015;2015(September 2014). doi:10.1155/2015/829526.

3. Fatimah I.;Journal of Advanced Research.
2016;7(6):961-969. doi:10.1016/j. jare.2016.10.002.

4. Lourdes M De; Abraham J; Cortez T, 2013,:1221-1228. 
5. Harivaindaran KV; Rebecca; Chandran S.; Pakistan Journal of Biological Sciences. 2008; 11(18):2259-2263.

6. Aziz FA; Noor MM.; Biomedical Research. 2009.

7. Demirbas A.;Welt BA ;Ocsoy I. ; Materials
Letters. 2016;179:20-23. doi:10.1016/j. matlet.2016.05.056.

8. Pacioni NL; Borsarelli CD; Rey V; Veglia A V. ; 2011. doi:10.1007/978-3-319-11262-6.

9. Ansari AQ; Ahmed SA; Waheed MA; A SJ; Abrar S.; 2013; 3(5):502-507. 